\title{
Controlling Mini Exhaust Fan through Android-Based Smartphone for IoT-Based Smart Home System
}

\author{
Syifaul Fuada ${ }^{1}$, Maulana Yusuf Fathany ${ }^{2}$, Trio Adiono ${ }^{3}$, Khilda Afifah ${ }^{4}$ \\ ${ }^{1}$ Program Studi Sistem Telekomunikasi, Universitas Pendidikan Indonesia, Bandung, Indonesia \\ ${ }^{2,3}$ The University Center of Excellence on Microelectronics, Institut Teknologi Bandung, Indonesia \\ ${ }^{4}$ Department of Function Control Systems, Shibaura Institute of Technology, Tokyo, Japan
}

\begin{abstract}
In this work, we present a control system for a mini electrical fan. The aim of this work is to design a controller prototype for an electrical fan within the smart home system. The system consists of an STM32L100 microcontroller for controlling the electrical fan using pulse-width modulation (PWM), TIP 102 BJT transistor for 'off,' and 'on' control of the fan, and 1N4007 fly-back diode. The PWM is generated by the STM32L100 microcontroller to control the Fan's speed softly $(25 \%, 50 \%, 75 \%$, and $0 \%-100 \%$ of speed). In addition, the system is equipped with a ZigBee module to support wireless communication with the host, which is required to receive and process commands from the Android application used for the user interface. Moreover, with the Zigbee module, the fan device enables be integrated wirelessly with other end devices in a smart home environment through a network (e.g., Mesh topology). Based on the testing performed, the system can work as intended, it can be controlled easily using Android smartphone and its speed, with the currents of $43.1 \mathrm{~mA}$ (idle mode) and $145.1 \mathrm{~mA}$ (processing mode) powered by $12 \mathrm{~V}_{\mathrm{DC}}$.
\end{abstract}

Keywords - DC-motor, Fan control, Smartphone, Smart Home

DOI: 10.18421/TEM103-37

https://doi.org/10.18421/TEM103-37

Corresponding author: Syifaul Fuada,

Program Studi Sistem Telekomunikasi, Universitas Pendidikan Indonesia, Bandung, Indonesia.

Email: Syifaulfuada@upi.edu

Received: 18 January 2021.

Revised: 20 June 2021.

Accepted: 29 June 2021.

Published: 27 August 2021.

(c) BY-NC-ND (C) 2021 Syifaul Fuada et al; published by UIKTEN. This work is licensed under the Creative Commons Attribution-NonCommercial-NoDerivs 4.0 License.

The article is published with Open Access at www.temjournal.com

\section{Introduction}

Electrical fan is one of the commonly used electronic appliance devices for air control, especially in the home environment. While not as potent as other electronic appliances such as air conditioner for temperature control, electrical fan has overall lower electricity cost and more environmentally-friendly nature due to not producing potentially dangerous substances for ozone layer. As such, electrical fan remains widely used, especially in residential areas for people with limited income and rented properties (i.e., lodgings). Several types of electrical fan are commonly used in residential areas which are elaborated in Table 1.

Table 1. Type of Fan and its characteristics

\begin{tabular}{|l|l|}
\hline Type & \multicolumn{1}{|c|}{ Characteristics } \\
\hline & $\begin{array}{l}\text { The fan draws fresh air from outdoor } \\
\text { then distribute it to the entire room it is } \\
\text { installed in. Works well with cool } \\
\text { outdoor temperature [1]. Generally, it can } \\
\text { be put in kitchen [2], main room/living } \\
\text { room [3], or bathroom. }\end{array}$ \\
\hline & $\begin{array}{l}\text { The fan is equipped with heating element } \\
\text { to allow warm air circulation to the room, } \\
\text { as well as being equipped with various } \\
\text { setting parameters to control temperature } \\
\text { and speed of the fan. }\end{array}$ \\
& $\begin{array}{l}\text { A fan type that generates air circulation } \\
\text { from the room the fan is installed in. } \\
\text { There are four sub-types of this fan: (a) } \\
\text { desk fan (medium wind speed, short } \\
\text { neck, and wide support platform); (b) } \\
\text { ceiling fan (permanently installed on } \\
\text { ceiling and no fan isolation/shield, the air } \\
\text { flows downward); (c) wall fan; and (d) } \\
\text { standing fan (supports rotating movement } \\
\text { and has long neck) }\end{array}$ \\
\hline
\end{tabular}

There have been several research projects for on/off and motor speed-based fan control. Some of the examples use wireless protocols such as: 
- Bluetooth [4], [5]

- ZigBee

- Radio Frequency [6]

- Wi-Fi

- SMS [7]

- Voice [8]

- Remote-less automated control [9]

- There is also an innovation of fan control movement based on human motion [10]

However, some of the existing works as mentioned above have limited functionality in the form of the standalone system. As such, this work aims to improve the functionality by design and implementation of remotely fan control on wireless sensor network (WSN) in the smart home system. It means that the fan device is connected with the others devices such as RGB lamp, humidity and temperature sensor, curtain, and smart plug in Mesh ZigBee network.

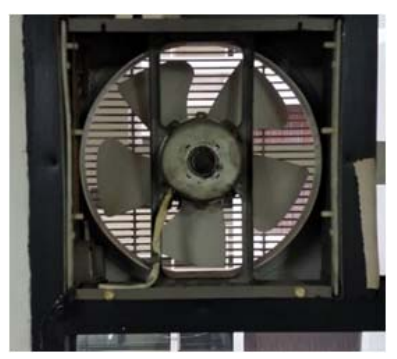

(a)

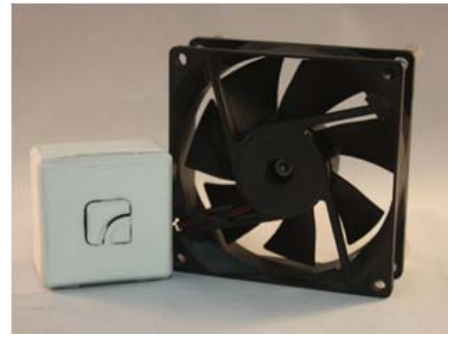

(b)
Figure 1. (a) Exhaust fan (Documented by S. Fuada, 2016); (b) small DC fan as representation for exhaust fan

In this work, the fan control system using on/off and PWM-based speed control is researched. The control for user will be conducted using smartphonebased application that provides slider-based or three buttons-based speed controls. The smartphone is not directly connected to the fan; instead, it is connected to a central host via Bluetooth, after which the host will process the command and send the result to the fan device through ZigBee network.

As the scope of this work consists of prototype for smart home system, a small device is used as representation for the home appliance to be controlled. Therefore, a small fan driven using DC motor is used as representation/model for exhaust fan commonly found on kitchen and bathroom wall. The DC motor works at $12 \mathrm{~V}_{\mathrm{DC}}$ and $0.14 \mathrm{~A}$. The representation of the device is depicted in Figure 1.

\section{Methodology}

\subsection{System Description}

Ideally, as part of a smart home system, the control and transmission of the commands for the fan should be secured and can be performed automatically based on specified parameters. However, as for this version, the pre-defined parameters (i.e., scheduling) and security measures are not yet implemented for the fan control. This paper's scope is limited to demonstrate the feasibility of controlling fan wirelessly through user's smartphone, while security measures and parameters such as scheduling will be defined and implemented in future work.

The system architecture for the fan control is depicted in Figure 2. In this work, the architecture is divided into three parts: Android-based application as user interface, host/gateway to bridge the end-device and the server, and end-node consisting several blocks as depicted in Figure 3. The working principle of the system is elaborated further in accompanying publications for this project [11], [12].

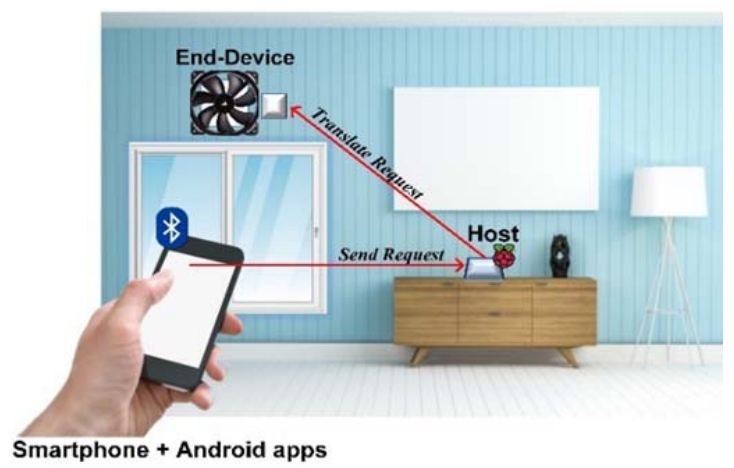

Figure 2. The architecture of fan control

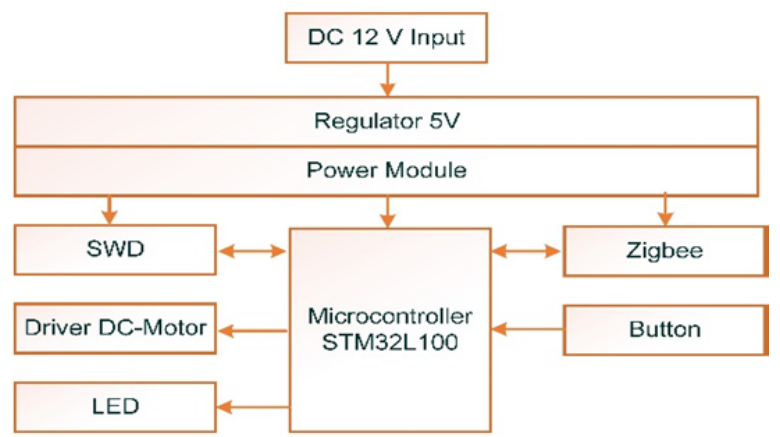

Figure 3. Hardware structure of Fan control system

In this work, the fan serves as one of the end-nodes to be controlled through the host. The fan's power is supplied using $12 \mathrm{~V}_{\mathrm{DC}}$ external adapter through DC jack interface. Some of the interface features offered consist of switch, reset and mode buttons, DC jack, output control port, and micro-USB port for firmware update. For control purposes, STM32L100 microcontroller is used in this project due to its low power usage.

For the host, Raspberry Pi 2 is used as a "bridge" for the end-nodes, the central server, and user interface application. The Raspberry Pi 2 consists 4 USB connectors and USART GPIO. For connectivity with the end-nodes, the Raspberry $\mathrm{Pi}$ unit is connected to a ZigBee module through the UART pin. The host works by processing commands from 
user's smartphone received through Bluetooth, then delivers the processing result to the end-nodes through ZigBee. For the user interface, an Androidbased smartphone application is developed using MIT App Inventor 2. Further details on the application development are elaborated in previous work.

\subsection{Hardware Design}

The structure of the hardware is elaborated in Figure 3, while the schematic diagram is depicted in Figure 4. In general, the hardware consists of a power module and $5 \mathrm{~V}_{\mathrm{DC}}$ regulator, STM32L100 microcontroller, and an electronic driver. The hardware operates by having the STM32L100 microcontroller to emit PWM signals through the controller's digital pin, which ranges from 0 to 3.3 $\mathrm{V}_{\mathrm{DC}}$. The speed of the fan is influenced by the PWM signals.

For the 'on' and 'off' switching of the fan, TIP 102 BJT transistor with high-side configuration is employed as switch. The transistor has Darlington configuration, as such it has $\mathrm{V}_{\mathrm{BE}}=1.4 \mathrm{~V}_{\mathrm{DC}}$ (obtained from the summation of $0.7 \mathrm{~V}_{\mathrm{DC}}$ with $0.7 \mathrm{~V}_{\mathrm{DC}}$ ) and power up to 80 Watt. When the voltage between $\mathrm{V}_{\mathrm{BE}}$ and ground is above $1.4 \mathrm{~V}_{\mathrm{DC}}$, the transistor will enter saturation region, causing the current from $\mathrm{V}_{\mathrm{CC}}$ to ground to pass DC motor and transistor, and vice versa.

Using the equation (1) for calculation, the base current $\left(I_{B}\right)$ required to switch the TIP 102 into saturation mode is identified to be $1.9 \mathrm{~mA}$ for $\mathrm{R}_{\mathrm{B}}=1$ $k \Omega$. As such, the $R_{B}$ value is used for switch operation of the transistor. Meanwhile, the power dissipation of the transistor is calculated using equation (2), resulting 0.28 watts power dissipation based on the values provided by the datasheet $\left(\mathrm{I}_{\mathrm{C}}=140 \mathrm{~mA}\right.$ and $\mathrm{V}_{\mathrm{CE}}=2 \quad \mathrm{~V}_{\mathrm{DC}}$ for saturation condition).

$$
\begin{aligned}
& I_{B}=\frac{V_{\text {Out }} \text { Microcontroller }-2\left(V_{B E}\right)}{R_{B}} \\
& P(\text { transistor })=V_{C E}(\text { sat }) * I_{C}
\end{aligned}
$$

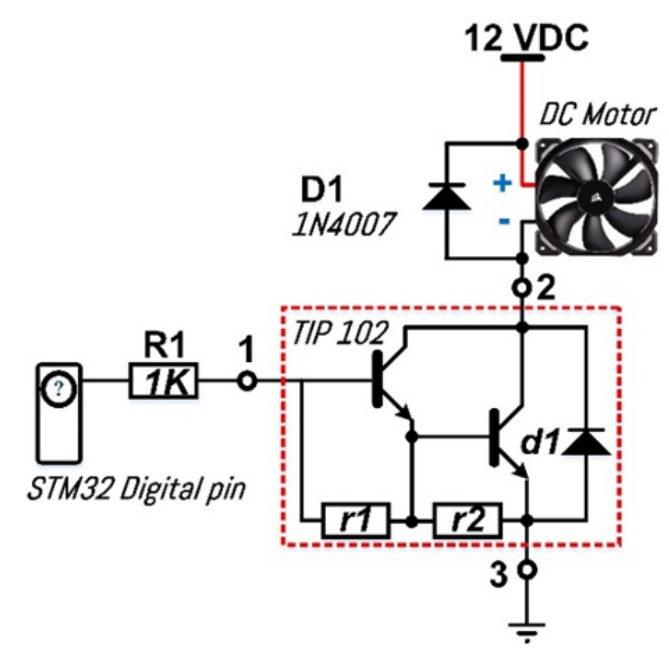

Figure 4. Electronic driver for Fan control in switch topology, the detailed calculation refers to previous work

As safety measure for the transistor, a 1N4007 diode is utilized as flyback diode. The purpose of the diode is to prevent damage from drastic current increment when the transistor switches from "on" mode to "off" mode.

\subsection{Software Design}

The flowchart for the fan control is depicted in Figure 5, while the flowchart for more specific control from the user interface is depicted in Figure 6. As this end-device is part of the designed smart home prototype, this work is related to other works described in [5]. To support connectivity with the devices described in the aforementioned works, ZigBee protocol is used to connect the devices in mesh topology. The command for the end-devices is sent from Android-based application, whether using hard control (fixed buttons such as for on/off purposes) or soft control (using slider). Afterwards, the host will process the command from the user interface, then relay the result to the fan to be executed.
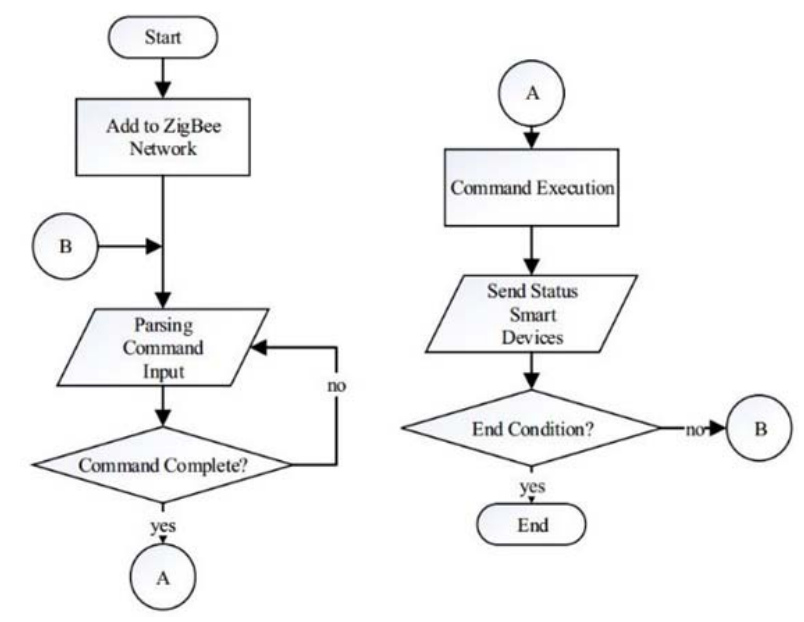

Figure 5. Flowchart of fan control works, obtained from previous work 


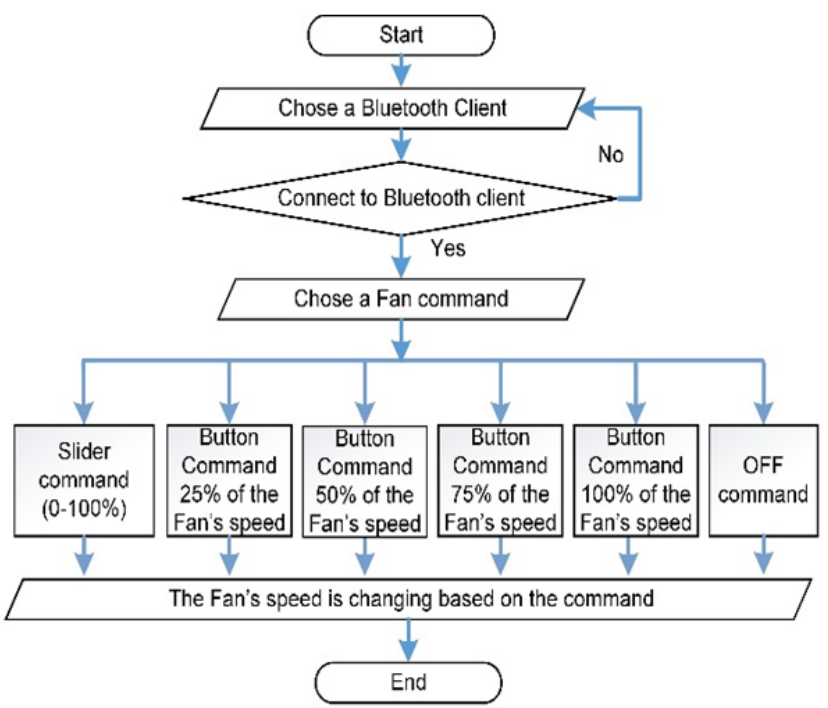

Figure 6. Flowchart for Android application, reproduced from previous work

\subsection{Protocol Design}

The communication protocol for this work utilizes format proposed in previous works. As depicted in Figure 7, the message consists of header (3 Bytes: 50, 4D, 45), device address (2 Bytes: 06, 3), packet initialization (1 Byte: 80 ), data payload (1 Byte: $0-$ $100 \%$ ), and checksum, as well as each section's respective byte allocations.

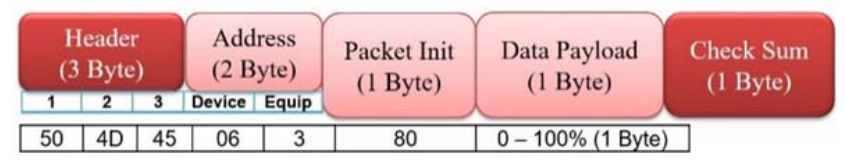

Figure 7. Packet data structure for Fan control, reproduced from previous work

\section{Results and Analysis}

\subsection{Implementations}

The printed circuit board (PCB) based on the schematic diagram in Figure 3 is presented in Figure 8 and Figure 9. The PCB has $40.21 \mathrm{~mm} \times 39.84 \mathrm{~mm}$ dimension. Figure 10 shows the custom-built of DC motor driver in which the implementation refers to the Figure 4. While Figure 11 shows the Host that employs Raspberry Pi and connected with Bluetooth module, XBee, and WiFi module (for long-range control/outdoor scenario). Table 2 shows the control command for fan device in STM32 Microcontroller.

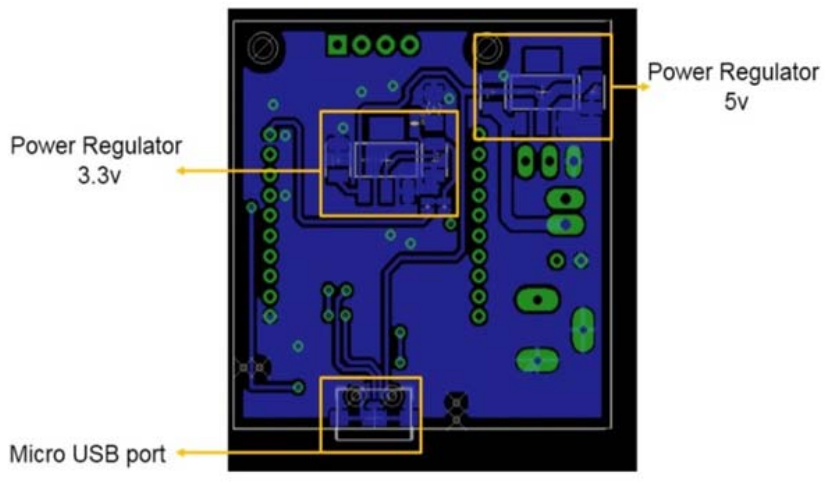

Figure 8. Bottom layer of the PCB design

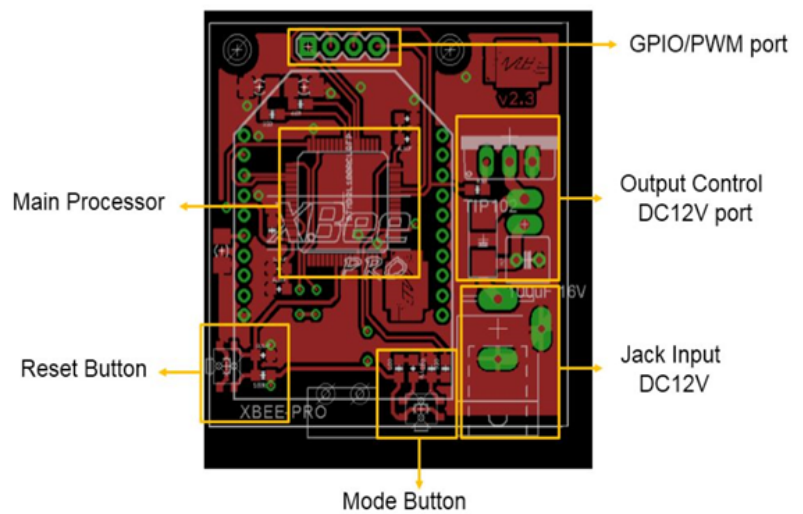

Figure 9. Top layer of the PCB design

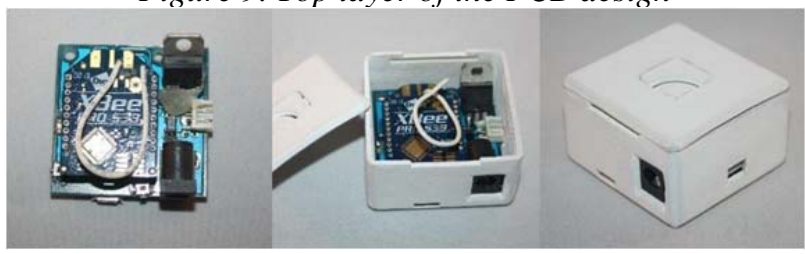

Figure 10. A photograph of implemented module

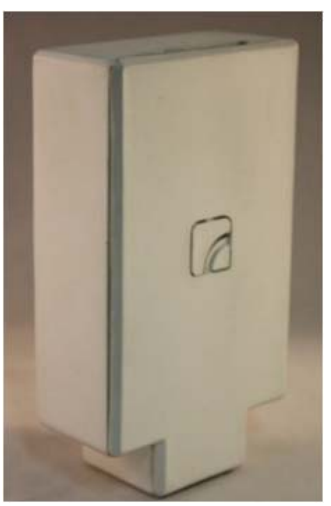

(a)

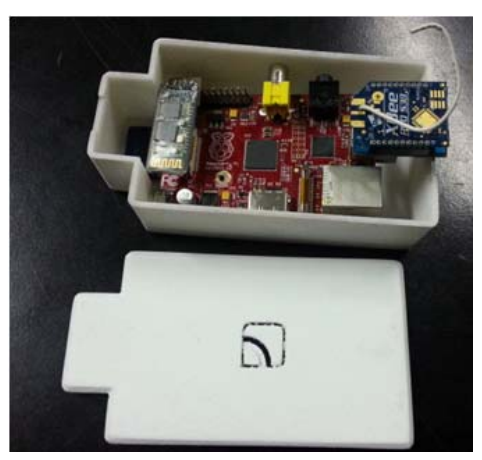

(b)
Figure 11. (a) host module in compact box; (b) the anatomy of the host containing Xbee module, Raspberry $\mathrm{Pi}$, Bluetooth module, and case 
Table 2. Control command for fan implementation

if $($ rawspeed $==\odot)$ TIM3 $->C C R 3=\odot ;$
else $\left\{k e c=(\right.$ rawspeed $/ 255){ }^{*} 500+50 \odot ;$
TIM3->CCR3=speed; $\}$

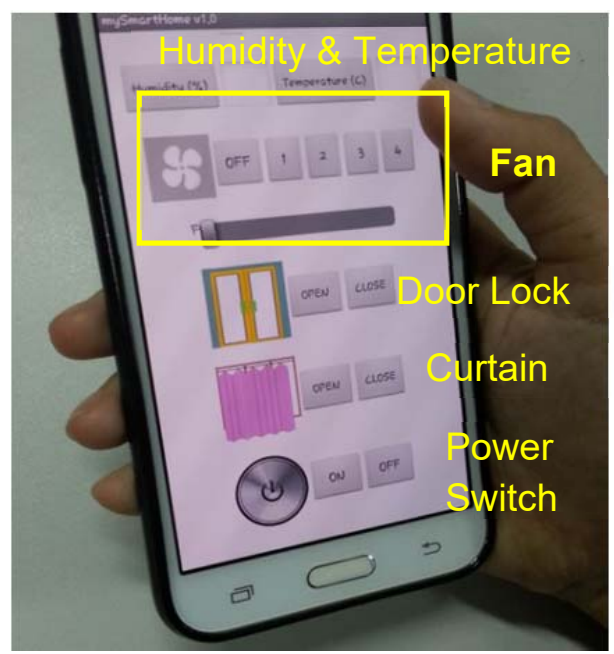

(a)

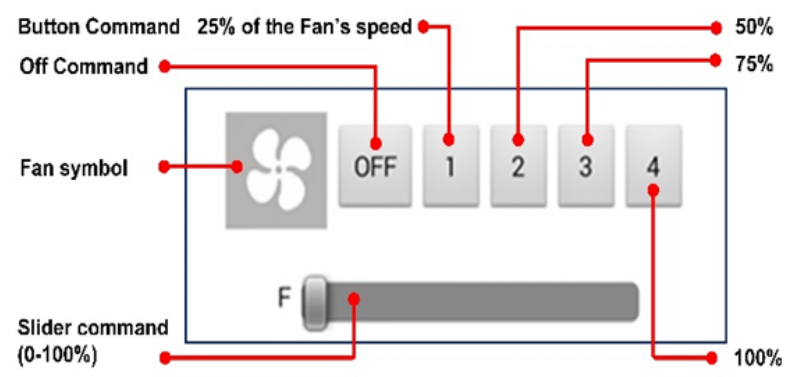

(b)

Figure 12. Screenshot of developed android apps for fan control

As previously explained in Section II, the PWM signal is generated by the STM32L100 microcontroller is used as reference for controlling the fan speed. The value is translated into byte value ranging from 0 to 255 for data payload, with 0 representing 0\% PWM and 255 representing 100\% PWM. The microcontroller's TIM3 is used for the timing, while the PWM configuration is described in previous work.

Figure 12(a) visualizes the Android application to control the fan for hard- and soft-control. The fan menu consists of four buttons and one slider as depicted in Figure 12(b).

\subsection{Testing}

The functional testing is conducted to ensure the on/off and speed control to work as intended. The testing process is depicted in Figure 13, while the testing result is elaborated in Table 3. After the functional test is conducted, the power dissipation of the device is measured when the device is both idle and in processing mode. The power dissipation is measured using power supply equipped with current and voltage displays. The result of the measurement is depicted in Table 4.

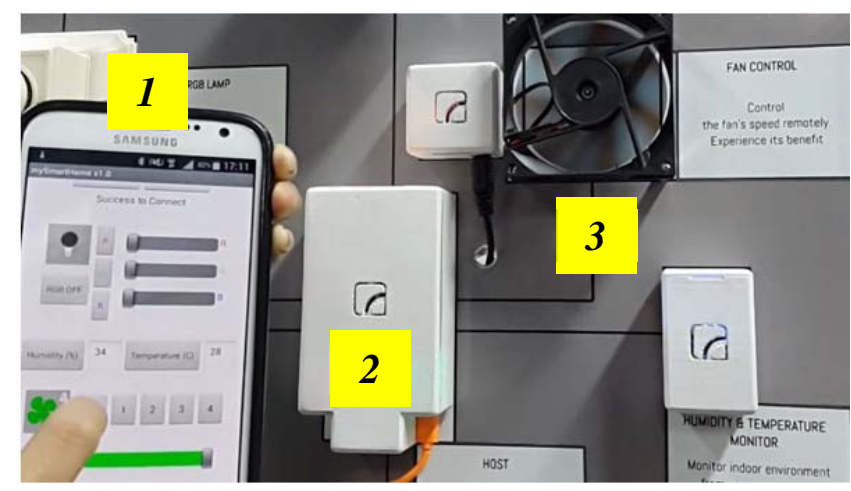

Figure 13. A setup for functional test of fan control including: (1) smartphone as a user interface; (2) host; (3) end-device, which is fan

Table 3. Results of Functional Test

\begin{tabular}{|c|c|c|}
\hline $\begin{array}{l}\text { Commands } \\
\text { on GUI }\end{array}$ & Condition setting & Results \\
\hline On (Speed I) & $\begin{array}{l}\text { Fan rotates in } 25 \% \text { of its } \\
\text { speed }\end{array}$ & $\sqrt{ }$ \\
\hline Speed II & $\begin{array}{l}\text { Fan rotates in } 50 \% \text { of its } \\
\text { speed }\end{array}$ & $\sqrt{ }$ \\
\hline Speed III & $\begin{array}{l}\text { Fan rotates in } 75 \% \text { of its } \\
\text { speed }\end{array}$ & $\sqrt{ }$ \\
\hline Speed IV & $\begin{array}{l}\text { Fan rotates in } 100 \% \text { of its } \\
\text { speed }\end{array}$ & $\sqrt{ }$ \\
\hline Off & Fan is stopped & $\sqrt{ }$ \\
\hline Slider & 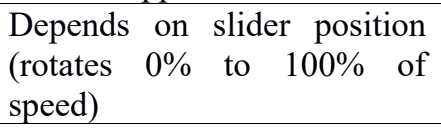 & $\sqrt{ }$ \\
\hline
\end{tabular}

Table 4. Power Measurement of Fan Device

\begin{tabular}{|c|c|c|}
\hline \multirow{2}{*}{$\begin{array}{c}\text { Input } \\
\text { voltage }\end{array}$} & \multicolumn{2}{|c|}{ Current } \\
\cline { 2 - 3 } & Idle condition & Process condition \\
\hline $12 \mathrm{~V}_{\mathrm{DC}}$ & $43.1 \mathrm{~mA}$ & $145.1 \mathrm{~mA}$ \\
\hline
\end{tabular}

\section{Conclusion}

In this work, a prototype of control system (with hard- and soft-control method) for electrical fan is designed for smart home system. The system utilizes STM32L100 microcontroller in order to support lowpower operation. Based on the testing conducted, the fan can be configured for various speed, and it requires $43.1 \mathrm{~mA}(517.2 \mathrm{~mW})$ in an idle condition and $145.1 \mathrm{~mA}(1,741.1 \mathrm{~mW})$ in a processing condition. 


\section{References}

[1]. Khairudin, M., Yatmono, S., Nashir, I. M., Arifin, F., \& Aulia, W. (2021). Exhaust Fan Speed Controller Using Fuzzy Logic Controller. In Journal of Physics: Conference Series (Vol. 1737, No. 1, p. 012046). IOP Publishing.

[2]. Dobbin, N. A., Sun, L., Wallace, L., Kulka, R., You, H., Shin, T., ... \& Singer, B. C. (2018). The benefit of kitchen exhaust fan use after cooking-An experimental assessment. Building and Environment, 135, 286-296. https://doi.org/10.1016/j.buildenv.2018.02.039

[3]. Munir, M., \& Erfianto, B. (2020, June). A Distributed Fuzzy Logic with Consensus for Exhaust Fan Controller. In 2020 8th International Conference on Information and Communication Technology (ICoICT) (pp. 1-6). IEEE.

Doi: 10.1109/ICoICT49345.2020.9166362

[4]. Purnamasari, I., \& Rezasatria, M. (2019). Rancang Bangun Pengendali Kipas Angin Berbasis Mikrokontroller Atmega 16 Melalui Aplikasi Android Dengan Bluetooth. Simetris: Jurnal Teknik Mesin, Elektro Dan Ilmu Komputer, 10(1), 147-160. https://doi.org/10.24176/simet.v10i1.2883

[5]. Ordila, R., \& Irawan, Y. (2020). Penerapan Alat Kendali Kipas Angin Menggunakan Microcontroller Arduino Mega 2560 Dan Sensor Dht22 Berbasis Android. Riau Journal Of Computer Science, 6(2), 101-106.

[6]. Sunny, J., Thomas, K. A., Jyothish, P. M., Jayaprakash, P. R., \& Sindhu, S. (2017, April). Design and implementation of RF controlled miniature fan. In 2017 International Conference on Circuit, Power and Computing Technologies (ICCPCT) (pp. 1-5). IEEE.
[7]. Risanty, R. D., \& Arianto, L. (2017). Rancang Bangun Sistem Pengendalian Listrik Ruangan Dengan Menggunakan Atmega 328 Dan Sms Gateway Sebagai Media Informasi. JUST IT: Jurnal Sistem Informasi, Teknologi Informasi dan Komputer, 7(2), 45-54.

[8]. Prasatia, W., \& Kamarudin, K. (2018). Kipas Angin Pengikut Manusia Berdasarkan Wajah. Jurnal Integrasi, 10(2), 74-79. https://doi.org/10.30871/ji.v10i2.906

[9]. bt Aripin, N., \& Othman, M. B. (2014, August). Voice control of home appliances using Android. In 2014 Electrical Power, Electronics, Communicatons, Control and Informatics Seminar (EECCIS) (pp. 142-146). IEEE.

[10]. Langi, S. I., Wuwung, J. O., \& Lumenta, A. S. (2014). Kipas Angin Otomatis Dengan Menggunakan Sensor Suhu. Jurnal Teknik Elektro dan Komputer, 3(5), 41-48.

[11]. Adiono, T., Putra, R. V. W., Fathany, M. Y., Lawu, B. L., Afifah, K., Santriaji, M. H., \& Fuada, S. (2016). Rapid Prototyping Methodology of Lightweight Electronic Drivers for Smart Home Appliances. International Journal of Electrical \& Computer Engineering (2088-8708), 6(5).

[12]. Adiono, T., Fathany, M. Y., Putra, R. V. W., Afifah, K., Santriaji, M. H., Lawu, B. L., \& Fuada, S. (2016, October). Live demonstration: MINDS-Meshed and internet networked devices system for smart home: Track selection: Embedded systems. In 2016 IEEE Asia Pacific Conference on Circuits and Systems (APCCAS) (pp. 736-737). IEEE. DOI: 10.1109/APCCAS.2016.7804031 